\title{
Do it standing up...
}

\author{
Lesley Smith
}

Tutbury Castle, Tutbury, UK

Correspondence to

Ms Lesley Smith, Tutbury Castle,

Tutbury, Staffordshire

DE13 9JF, UK;

info@tutburycastle.com

Received 17 February 2011

Accepted 18 February 2011

\section{Old wives" tales}

The concept of oral tradition is well known by historians, and I have learned over the years that to dismiss such evidence as merely unsubstantiated rumours can lose threads of important research. A little lateral thinking, using the oral tradition as a base, can lead to some fascinating findings that have written and pictorial evidence to support the theory.

The study of the history of medicine has more than its fair share of 'old wives' tales', many of which can be found in our own families and are often clung to like heirlooms. No doubt these beliefs have been a source of irritation over the centuries to highly qualified physicians when they learn that their diagnosis and treatment has been overturned by a potion from Grandma, who "swears by it".

As one might expect, conditions that involve private parts of the body are more likely to have quack medicine associated with them, as people could be just too embarrassed to consult a doctor then, as indeed many people still are today.

There can be some surprising results from analysing these ideas and treatments. 'Old wives' tales' can produce evidence of medical philosophies passed from generation to generation for hundreds and even thousands of years. The oral tradition can remain unbroken while the written version fell by the wayside many years before, and it is that continuity of ideas that I will address in this article.

In the late 1970s, I heard two women in a gynaecological ward discussing the removal of an ovary booked as a procedure the next day for one of them who was only in her 20s. The whole conversation was about whether the left or right ovary "contained boys" as the young woman in question particularly wanted a girl. I knew when I heard that conversation that the women were discussing the theories of Soranus, a Greek physician who lived in AD 98-138. By the mid-16th century, Soranus' ideas were already notorious and medical thinking had moved on. However, apparently not everywhere, as that particular belief was alive and well, just over 30 years ago in Staffordshire.

\section{Sexual positions and pregnancy}

The idea that having sex standing up, from behind or with the woman sitting astride the man would prevent conception was once part of serious medical belief and can be found in ecclesiastical law as forbidden sexual positions right back to the early medieval period.

Although gravity and most of the laws of physics were not understood at that time, the simple fact that water did not flow uphill and semen therefore could not either was enough to provide evidence that a couple having sex in such a way must be trying to avoid pregnancy. Sex for pure pleasure and not just for the purposes of procreation was sinful according to church law and punishable as lewd and lustful. As canon law and not civil law handled cases related to sexuality in special courts, it was their view that counted and the punishments meted out could be cruel and humiliating.

Rapid jumping up and down after intercourse was, and possibly still is, practised by some women keen to avoid pregnancy. It is more involved than simply arguing such an action is an attempt to shake semen from the body, as it was also believed that a pregnancy could be terminated in this way. Some women who were slow in labour were told to go up and down stairs shouting as loudly as possible. I have evidence of this in a hospital in England in 1942 and also in a textbook dating from the 16th century. Gin and hot baths seem to be known by all within the British Isles as being able to cause a pregnancy termination.

\section{Contraception methods and myths}

Pellets of bread pushed into the vagina to serve as a barrier seems to be more to do with accessibility, speed and cheapness than anything else. Garlic, however, is another matter. The idea that the womb 
is alive like a little creature is found in the teachings of Hippocrates, dating back to around 460 BC. The idea that the womb would flee from bad smells and be attracted towards good smells such as incense and perfumes is well known in ancient medicine and was believed right up to the Age of Enlightenment.

Aristotle's Masterpiece is a publication I have mentioned in previous articles. It presents itself as a medical textbook but is full of quackery, even by the standards of the day. Thought to be originally published in the late 17 th century, it remained in print in one form or another, right up until the early 20th century and was, it seems, found in many homes, although discreetly shelved. The work discusses sex and menstruation, monstrous births and "disturbed pregnancies". Despite the years of enlightenment and real findings of science completely overturning many of the beliefs published in Aristotle's Masterpiece, it was still clung to, as evidenced by the repeated reprints over centuries.

Away from published advice in books, we know that women of many ages practised contraception. Natural sponges dipped in vinegar would be known to Roman matrons and, centuries later, Fanny Hill used sponges soaked in oil. Flushing semen out of the vagina with a jet of water (a douche) was widely used.

Recently, after a talk, I was privileged to meet a sexual health nurse who had been practising in the early 1950s and she told me what a struggle it could be to be taken seriously compared to other areas of nursing. She was the grand-daughter of a famous Northern suffragette, and she told me her grandmother had managed her fertility by the use of a sponge kept in a jar of oil, with a thread through the centre of the sponge for easy removal after intercourse.

In our lifetime we will have heard a range of contraception myths ranging from the sublime to the ridiculous, such as keeping your knickers on and having intercourse through them, avoiding sex at the time of a full moon, and the woman ensuring she didn't have an orgasm or she may be punished with an unwanted pregnancy for being sinful and impure.

Chicken skin has received much publicity recently as a makeshift condom and simply links with the use of gut condoms; while cling film and crisp packets used with baby oil are apparently widely known options for use as condoms. Young people tell me this and just shrug when I ask them why they don't just visit their local family planning clinic. Although contraception is freely available in the UK, people can still sometimes be more inclined to trust tales passed from one person to another in a medical marketplace made up of myth and hearsay, rather than putting their trust in qualified medical professionals.

\section{Future articles}

The next article in this series will consider 'The History of Rape', and will examine the society of the time's attitudes to rape.

\section{About the author}

Lesley Smith is currently a postgraduate student in the Centre for the History of Medicine of the University of Birmingham, where she is developing a $\mathrm{PhD}$ in obstetrics and gynaecology in early modern Britain. She holds an honorary degree for 'services to history'. She makes 200-300 public appearances a year and also works as a TV historian in the UK and abroad including the USA. Lesley is also Curator of Tutbury Castle in Staffordshire and is a member of the Society of Apothecaries of London, the Society of Medical Writers and is a recent Fellow of the Society of Antiquaries of Scotland (FSA Scot).

Acknowledgements The author would like to thank Dr G Williams, British Museum, London, UK for his help and advice. Unfortunately, Lesley failed to obtain the contact details of the sexual health nurse mentioned in the article, and would greatly appreciate any help in locating her.

Competing interests None.

Provenance and peer review Commissioned; internally peer reviewed.

\section{Bibliography}

1 Aristotle's Masterpiece, also known as The Works of Aristotle, the Famous Philosopher, is a sex manual and a midwifery book that was popular in England from the early modern period through to the 19th century. It was first published in 1684. The book is of unknown authorship, but was erroneously attributed to Aristotle and was banned in Britain until the 1960s.

2 Eccles A. Obstetrics and Gynaecology in Tudor and Stuart England. London, UK: Croom Helm Ltd, 1982. 